\title{
PARAMETRIC STUDY OF THE EFFECT OF DEAD LOADS ON BEAM NATURAL FREQUENCIES
}

\author{
Mohamed Abdel-Basset Abdo \\ Civil Engineering Department, Faculty of Engineering, Assiut University, \\ Assiut, Egypt
}

(Received June 14, 2008 Accepted July 26, 2008)

\begin{abstract}
One of the hot research topics nowadays is structural health monitoring. The most useful damage location methods (based on dynamic testing) are probably those using changes in resonant frequencies. This study is concerned with parametric study of the effect of dead loads on the natural frequencies of beams. The study includes two types of dead loads; distributed and concentrated loads for different models. The first ten mode frequencies are studied for each model. Based on the numerical results, it is shown that both distributed and concentrated loads have considerable influence on the lower frequencies of beams, especially the fundamental one. Also, it is found that the influence of dead loads on beam frequencies depends on cross- section moment of inertia and span-length. Furthermore, it is found that the effect of dead loads decreases with the increase of number of beam spans. Also, certain cases of loadings provide high change of frequencies due to dead loads. On the other hand, the percentage changes of frequencies due to dead loads with different values of mass density and modulus of elasticity are the same.
\end{abstract}

KEYWORDS: Parametric study, dead loads, beam natural frequencies, mass density, and modulus of elasticity.

\section{INTRODUCTION}

The basic concept in linear, vibration-based damage detection is that global modal parameters (resonant frequencies, mode shapes, and modal damping) are functions of the physical properties of the structure (mass, damping, and stiffness). Therefore, changes in the physical properties will cause changes in the modal characteristics and the measured response of the structure, [1]. Over the past few decades, major advances have been realized in the fields of structural dynamics and experimental modal analysis. Knowledge of structural dynamic characteristics allows one to diagnose vibration problems, evaluate the effects of different loading conditions, examine the effects of perturbations in structural properties, and to control the behaviour of the structure. So, precise and detailed knowledge of the dynamic characteristics of structures has become increasingly important in recent years [2]. Indeed, the most useful damage location methods (based on dynamic testing) are probably those using changes in resonant frequencies because frequency measurements can be quickly conducted and are often reliable. Another advantage is the global nature that allows the measurement points to be chosen to suit the test situation. Salawu [3] gave a literature review of the state of the art of damage detection using changes in natural frequencies. 
In structural health monitoring using vibration-based damage detection methods, data acquisition could take a significant amount of time. During that time, changes in structural characteristics can occur due to environmental changes (temperature, humidity, wind) and/or additional dead loads, which may cause large variations in the vibration response at the same structural point. In contrast to live loads, dead loads are stationary and produce initial stresses. The strain energy resulting from these stresses should be considered in addition to the well-known strain energy produced by live loads. The strain energy produced by initial stresses reduces the displacements and internal forces produced by live loads. Actually, the beam is the main component of most civil structures, e.g., buildings, bridges, cranes, etc. So, the fundamental frequencies of a beam are of general significance.

Because little is known concerning its nature, the effect of dead loads on natural frequencies of structures is currently ignored in most previous beam studies, for example Chandrasekaran [4] and Thomson [5] ignored the effect of dead loads. Takabatake [6] studied the effect of dead loads on the natural frequencies of beam and proposed a closed-form approximate solution of the natural frequencies of simply supported beams. Because of the difficulty of using Takabatake's solution methods for complex structures, Zhou and Zhu [7] developed the conception and formulation of load-induced stiffness matrix of a beam element for the finite element method. Takabatake [8] extended the elementary plate theory and analyzed the effects of dead loads in dynamic plates. However, it is difficult to use Takabatake's approaches for complex plate or shell structures. Zhou [9] derived load-induced stiffness matrix of a rectangular plate element which is more easily applied to practical structures subjected to various support conditions. Cornil et al. [10] investigated the natural frequencies of cantilever beams and made a comparison between the natural frequencies of statically deformed beams and the naturally curved beams that have the same initial shape. They found that they have different frequencies and there is not any general relationship between their frequencies. Unfortunately, a parametric study of the influence of dead loads on natural frequencies of structures has been lacking.

The objective of this paper is to investigate the influence of different major parameters of dead loads on beam natural frequencies. Indeed, a better understanding of dead load effect will lead to a more accurate estimate of the effects of live loads; thus truly safe structural designs will be possible. A careful numerical study is carried out by using the finite element method. The parametric study includes the effect of uniform distributed and concentrated dead loads on frequencies of simply supported beam with varying moment of inertia, mass density, modulus of elasticity, and span length. Also, the frequencies of continuous-equal-span beams with different cases of loadings of dead loads are thoroughly studied.

\section{THEORETICAL BACKGROUND}

For simplicity, assume a beam shown in Fig. 1 with a Cartesian coordinate system: the $x$-axis passes through the centroidal axis of the beam, and the $y$-and $z$-axes are the principal axes of cross section for the beam. The following assumptions are used: the beam is straight without initial imperfections; the external loads acting on the beam are transverse loads; and axial forces are absent. Also, the static transverse deflection $v_{D}$. is 
produced by a dead load per unit length $w_{D}$. This deformed state is defined as the reference state of the beam. A dynamic live load per unit length $w_{L}$ acting on this reference state produces a dynamic deflection $v_{L}$ where $v_{L}$ is measured from the reference state. The deflections $v_{D}$ and $v_{L}$ and transverse loads $w_{D}$ and $w_{L}$ are considered positive when they point in the positive direction of the $y$-axis.

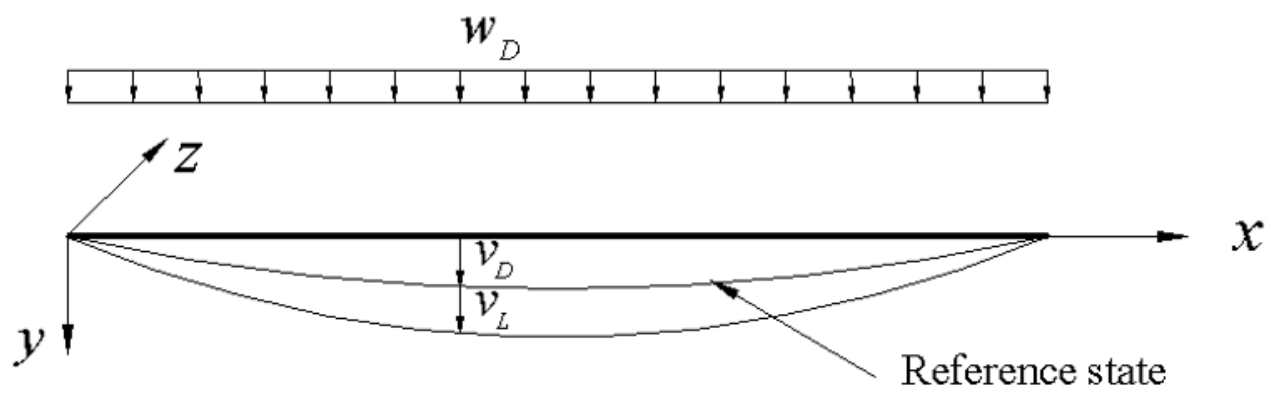

Figure 1: Coordinates and dead load distribution of beam.

The strain energy, $U$ of the beam element can be expressed as follows [6]:

$$
U=U_{D}+U_{L},
$$

where $U_{L}$ is the strain energy produced by live loads $w_{L}$ and $U_{D}$ is the additional strain energy resulting from the conservative initial bending stresses produced by dead loads $w_{D}$. For the strain energy $U_{L}$, the linear strain-displacement relation is used. However, the nonlinear strain-displacement relation is used to introduce the effect of dead load. The dynamic equation for beam elements is obtained as follows:

$$
F=M\left(K_{e}+K_{D}-K_{g}\right) \delta-F_{e q},
$$

or

$$
F=M K \delta-F_{e q},
$$

in which $\delta$ is the element nodal displacement vector, $F$ is the element nodal force vector, $M$ is the consistent mass matrix, $K_{e}$ is the elastic stiffness matrix, $K_{D}$ is the dead load-induced stiffness matrix, $K_{g}$ is the geometric stiffness matrix, $F_{e q}$ is the element equivalent concentrated force vector due to live load, and $K$ is the element stiffness matrix including the effects of dead loads and axial compressive forces, and is given as follows:

$$
K=K_{e}+K_{D}-K_{g},
$$

From Eq.(3) it can be seen that the dead loads increase the bending stiffness of the beam. However, the axial compressive forces decrease the bending stiffness of the beam. 


\section{FINITE ELEMENT ANALYSIS}

The finite-element modeling in the present study was carried out using the MARC/Mentat package [11], [12]. The basic model is a simply supported steel beam. The beam is assumed to have uniform cross sectional area and $30[\mathrm{~m}]$ span length. The cross sectional area of the beam and the moments of inertia are, $A=0.07\left[\mathrm{~m}^{2}\right]$, and $I_{z}=$ $0.040\left[\mathrm{~m}^{4}\right], I_{y}=0.001\left[\mathrm{~m}^{4}\right]$, respectively. The mechanical properties of the steel beam are, modulus of elasticity, $E=210[\mathrm{GPa}$ ], Poisson's ratio, $v=0.3$, and the density, $\rho=7,850\left[\mathrm{~kg} / \mathrm{m}^{3}\right]$. Two-node beam element (element 52) with six degrees of freedom per node is used. The natural frequencies of the beam are calculated numerically for the first ten modes. This example is quoted from a simulated study by Abdo [13].

To verify the accuracy of the numerical simulation, three different meshes are studied for the steel beam; 10, 20, and 30 beam elements. Two types of dead loads are studied; a uniform distributed load and a concentrated load at mid span. The numerical results obtained for the frequencies of the steel models are compared with those obtained by other researchers. Indeed, the obtained results agree well with the reference results for all meshes. However, the results of the third mesh provides difference less than $0.1 \%$ of the results obtained by Takabatake [8]. Therefore, finite element analysis based on 30 equal elements for each span of the beam model is satisfactory for numerical investigation of natural frequencies.

\section{PARAMETRIC STUDY}

The present investigation considers the effect of a number of design variables on the natural frequencies of simply-supported and continuous beams including uniform distributed dead load, concentrated dead load with varying moment of inertia, mass density, modulus of elasticity, and span length. Also, the frequencies of two, three, four, and five continuous spans are investigated. Furthermore, the effect of different cases of loadings of dead load on the frequency of multi-span beams are thoroughly studied.

A large number of finite element models were constructed, and normalizing techniques were used to help generalize the results. For all models, the first ten natural frequencies of the system are calculated with the physical and mechanical properties mentioned above. When investigating the influence of one parameter on beam frequencies, other parameters are kept constant to isolate which parameters are significant in the design sense. In the following discussion, the normalized distributed load, $\bar{w}_{D}$ and normalized concentrated load, $\bar{P}_{D}$ are estimated as follows:

$$
\begin{gathered}
\bar{w}_{D}=\frac{w_{D} l^{3}}{E I}, \\
\bar{P}_{D}=\frac{P_{D} l^{2}}{E I},
\end{gathered}
$$

where $w_{D}=$ distributed dead load, $P_{D}=$ concentrated dead load at mid span, $l=$ span length, $E=$ modulus of elasticity, and $I=$ cross sectional moment of inertia about the major axis, $z$. The normalized dead load is varied from 0.0 to 1.0. Also, the percentage change in frequency is calculated as follows: 


$$
\text { Percentage increase in frequency }=\left(\frac{f_{n D}-f_{n 0}}{f_{n 0}}\right) \times 100,
$$

where $f_{n D}=$ the $n$th natural frequency including the effect of dead load and $f_{n 0}=$ the $n$th natural frequency excluding the effect of dead load.

\section{RESULTS AND DISCUSSIONS}

The following description summarizes the effects that the parameters mentioned previously have on beam frequencies.

\subsection{Uniform Distributed and Concentrated Dead Loads}

Figure 2 shows the relationship between the normalized distributed load and the change in natural frequencies of simply supported beam for the first five modes. The normalized distributed load and the percentage increase in frequency is calculated as stated in Eq.(4) and Eq.(6), respectively. It is shown that the natural frequency increases with the increase of distributed dead load. This is expected because the dead load increases the stiffness of the beam as mentioned in Eq. (3). Also, it is shown that the percentage increase of frequency is high for fundamental frequency and less for frequencies of higher modes. Moreover, it can be seen that the effect of uniform dead load is very small and may be neglected for frequencies higher than the first five natural frequencies.

To show the effect of concentrated dead load on beam frequencies, the relationship between the normalized concentrated dead load and the change in natural frequencies of simply supported beam for the first five modes are shown in Figure 3. The concentrated dead load is assumed to act at mid span of the beam and its value is assumed to provide the same bending moment on the beam obtained by the uniform distributed dead load. The normalized concentrated load and the percentage increase in frequency is calculated as mentioned in Eq.(5) and Eq.(6), respectively. Indeed, the effect of concentrated dead load is similar to that of uniform distributed load. Thus, the natural frequency increases with the increase of concentrated dead load and the percentage increase of frequency are high for fundamental frequency. Moreover, it can be seen that the effect of concentrated dead load is small for higher modes and may be neglected for frequencies higher than the first five natural frequencies.

From Fig. 2 and Fig. 3 it can be easily seen that both distributed and concentrated loads increase the beam frequencies due to the increase in the stiffness of the beam. This effect is apparent in beam fundamental frequency. Though the value of the concentrated load at mid span of the beam provides the same bending moment as that resulted under the uniform distributed dead load, the effect of uniform distributed load on the percentage increase of beam frequencies is higher. Only the effect of dead loads on the beam fundamental frequency will be considered in the following discussions. 


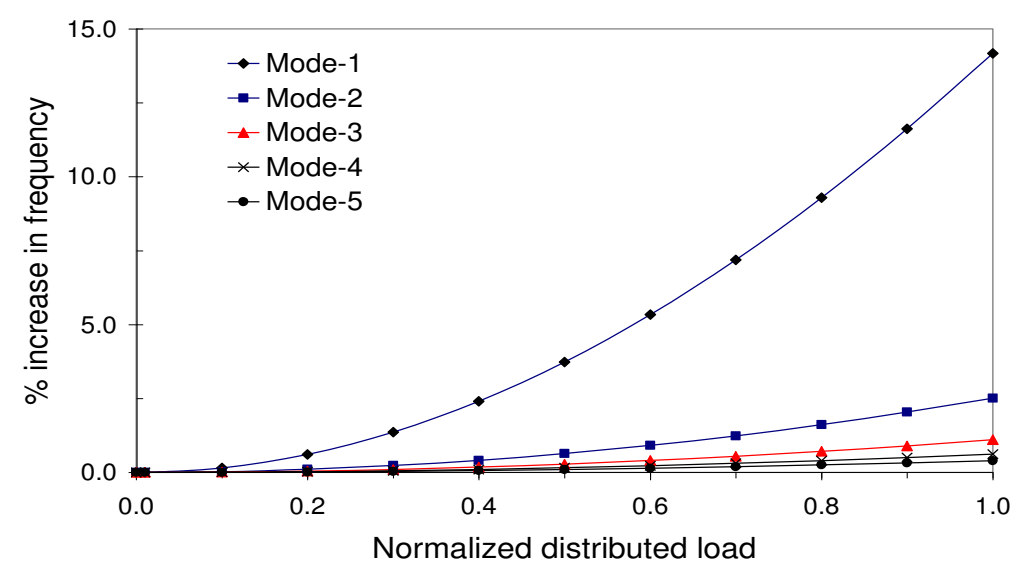

Figure 2: Relationship between distributed dead load and change in beam frequencies for different modes.

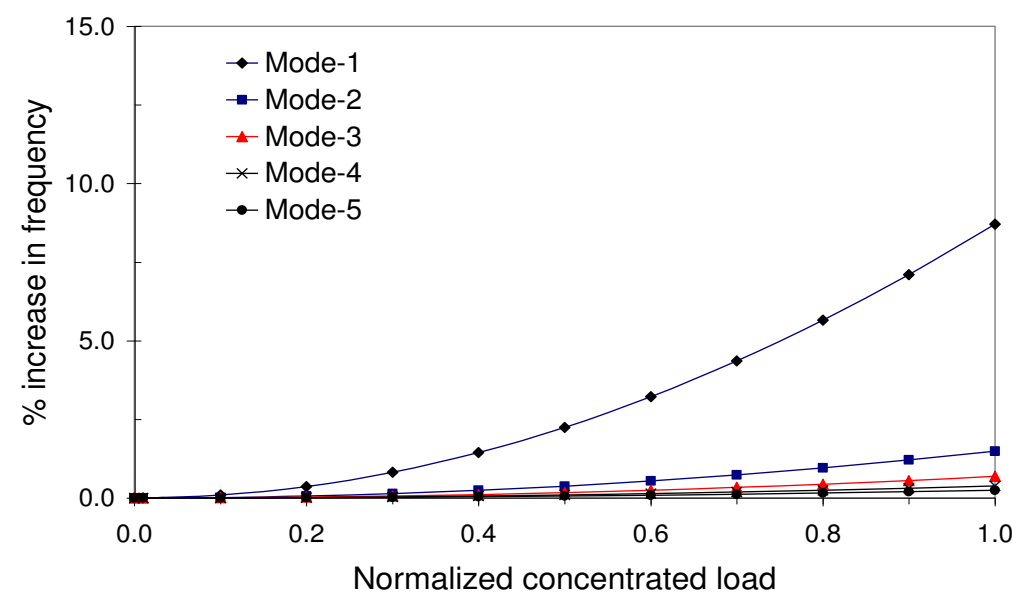

Figure 3: Relationship between concentrated dead load and change in beam frequencies for different modes.

\subsection{Span Length}

To determine the effect of dead loads on beam frequencies taking into account the span length, models were created with varying span lengths; $1.25 l, 1.0 l$, and $0.75 l$, where $l$ $=30[\mathrm{~m}]$. The relationship between the normalized distributed dead load and the change in fundamental frequency of simply supported beam for different spans are shown in Figure 4. The results show that for all span lengths the beam frequencies increase with the increase of dead loads. Also, as the span length increases the change in beam fundamental frequency increases. So, the longer the span the more effect of dead load on beam frequencies. Indeed, it is important to mention that as the span length increases the beam frequencies decrease since the beam stiffness is decreased. However, the change in beam frequencies increases with the increase of span length. Similar results are obtained for beams subjected to concentrated dead loads. 


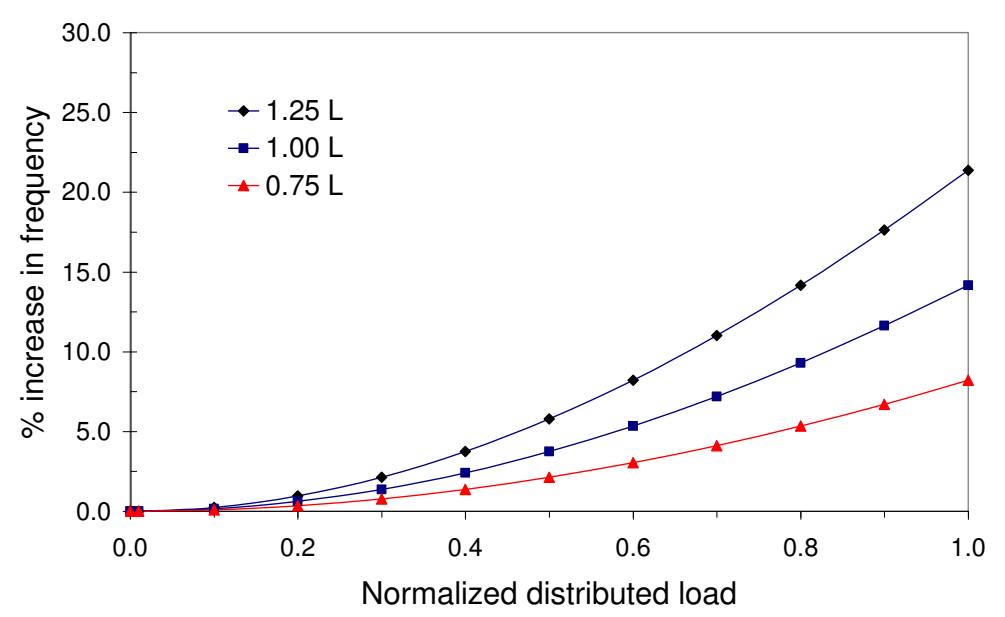

Figure 4: Relationship between distributed dead load and change in beam fundamental frequency for different span lengths.

\subsection{Moment Of Inertia}

To determine the effect of dead load on beam frequencies taking into account the cross sectional moment of inertia $I_{z}$, models were created with varying moment of inertia; $0.5 I, 1.0 I$, and $2.0 I$, where $I=0.040\left[\mathrm{~m}^{4}\right]$. The relationship between the normalized distributed dead load and the change in fundamental frequencies of simply supported beam with different moments of inertia is shown in Figure 5. It is easily seen that the beam frequencies increase with the increase of dead loads for all moments of inertia. Also, the change in beam frequencies increases with low cross sectional moment of inertia. So, the higher the moment of inertia the lesser the effect of dead load on beam frequencies. Indeed, it is important to mention the fact that beams with higher cross sectional inertia have higher stiffness and consequently have higher natural frequencies.

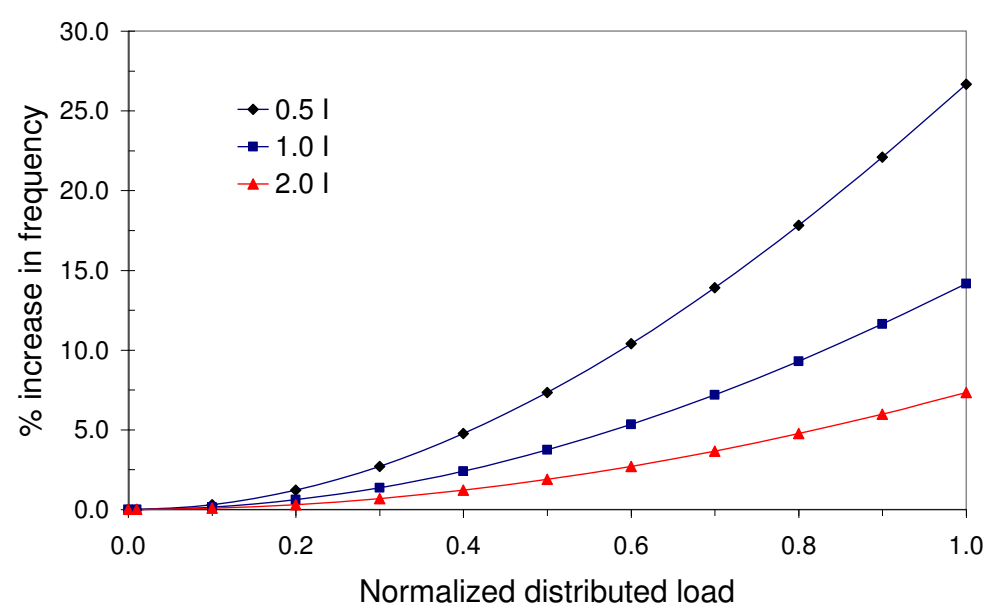

Figure 5: Relationship between distributed dead load and change in beam fundamental frequency for different cross sectional moments of inertia. 


\subsection{Modulus of Elasticity and Mass Density}

To investigate the effect of dead load on beam frequencies taking into account the properties of material, models of simply supported beams were created with varying modulus of elasticity, $E$ and mass density, $\rho$. The beam frequencies are estimated for $E=210[\mathrm{GPa}]$ and $E=21$ [GPa]. Also, the beam frequencies are estimated for $\rho=7,850$ $\left[\mathrm{kg} / \mathrm{m}^{3}\right]$ and $\rho=2,500\left[\mathrm{~kg} / \mathrm{m}^{3}\right]$. Table 1 and Table 2 show the effect of distributed dead load on the first five beam frequencies for different values of modulus of elasticity, $E$ and mass density, $\rho$, respectively. The beam frequencies are estimated under normalized distributed load $=1.0$.

From Table 1 it is easily seen that different values of modulus of elasticity $E$, give different values of beam frequencies for both cases of including or excluding the effect of dead loads. Of course, an increase in modulus of elasticity leads to an increase in beam frequencies and vice versa. However, the ratios $f_{n D} / f_{n 0}$ are the same for different values of $E$ and the change is higher for low frequency modes. Also, Table 2 shows that different values of mass density $\rho$, give different values of beam frequencies for both cases of including or excluding the effect of dead loads. Moreover, an increase in the mass density results in a decrease in beam frequencies and vice versa. However, and similar to Table 1, the ratios $f_{n D} / f_{n 0}$ are the same for different values of $\rho$. Thus, the percentage change in beam frequencies due to specific dead load does not depend on value of modulus of elasticity or mass density.

Table 1: Effect of dead load on the frequencies of a simply supported beam for normalized distributed load $=1.0$ for different values of modulus of elasticity, $E$.

\begin{tabular}{|c|c|c|c|c|c|c|}
\hline \multirow{2}{*}{$\begin{array}{c}\text { Modulus } \\
\text { of elasticity }\end{array}$} & \multirow{2}{*}{$\begin{array}{c}\text { Frequency } \\
E[\mathrm{GPa}]\end{array}$} & & \multicolumn{5}{|c|}{ Mode number } \\
\cline { 3 - 7 } & & 1 & 2 & 3 & 4 & 5 \\
\hline & $f_{n 0}$ & 6.82391 & 27.2957 & 61.4156 & 109.185 & 170.607 \\
210 & $f_{n D}$ & 7.79079 & 27.9798 & 62.0945 & 109.861 & 171.278 \\
& $f_{n D} / f_{n 0}$ & 1.1417 & 1.0251 & 1.0111 & 1.0062 & 1.0039 \\
\hline & $f_{n 0}$ & 2.15791 & 8.6317 & 19.4213 & 34.5273 & 53.9505 \\
21 & $f_{n D}$ & 2.46366 & 8.8480 & 19.6360 & 34.7410 & 54.1627 \\
& $f_{n D} / f_{n 0}$ & 1.1417 & 1.0251 & 1.0111 & 1.0062 & 1.0039 \\
\hline
\end{tabular}

Table 2: Effect of dead load on the frequencies of a simply supported beam for normalized distributed load $=1.0$ for different values of mass density, $\rho$.

\begin{tabular}{|c|c|c|c|c|c|c|}
\hline \multirow{2}{*}{$\begin{array}{c}\text { Density, } \rho \\
{\left[\mathrm{kg} / \mathrm{m}^{3}\right]}\end{array}$} & \multirow{2}{*}{ Frequency } & \multicolumn{5}{|c|}{ Mode number } \\
\cline { 3 - 7 } & & 1 & 2 & 3 & 4 & 5 \\
\hline \multirow{3}{*}{7850} & $f_{n 0}$ & 6.82391 & 27.2957 & 61.4156 & 109.185 & 170.607 \\
& $f_{n D}$ & 7.79079 & 27.9798 & 62.0945 & 109.861 & 171.278 \\
& $f_{n D} / f_{n 0}$ & 1.1417 & 1.0251 & 1.0111 & 1.0062 & 1.0039 \\
\hline \multirow{3}{*}{2500} & $f_{n 0}$ & 12.0920 & 48.3680 & 108.8290 & 193.476 & 302.316 \\
& $f_{n D}$ & 13.8053 & 49.5803 & 110.0320 & 194.674 & 303.505 \\
& $f_{n D} / f_{n 0}$ & 1.1417 & 1.0251 & 1.0111 & 1.0062 & 1.0039 \\
\hline
\end{tabular}




\subsection{Number of Spans}

To show the effect of dead load on fundamental beam frequencies taking into account the number of spans, a series of models were developed with one, two, three, four, and five equal spans. Each span is assumed to be 30 [m] length. Figure 6 shows the relationship between the normalized distributed dead load and the change in fundamental frequencies of beams with different number of spans. It is assumed that the distributed dead load acts on all spans for multi-span beams. It is shown that the beam frequencies increase with the increase of dead loads for all spans. Also, the change in beam frequencies is higher for single span and the change in frequencies decreases significantly as the number of spans increases. Thus, it is seen that the change in frequency for single span is nearly six times that of the multi-span beams. Thus, for distributed dead load over all spans, continuous beams have small changes in frequencies. Indeed, it is important to mention that the fundamental frequencies of all these beams are the same. So, the effect of dead load is maximum for single span and is much smaller for multi spans with all spans loaded. Similar results are obtained for beams subjected to concentrated dead loads at their mid spans.

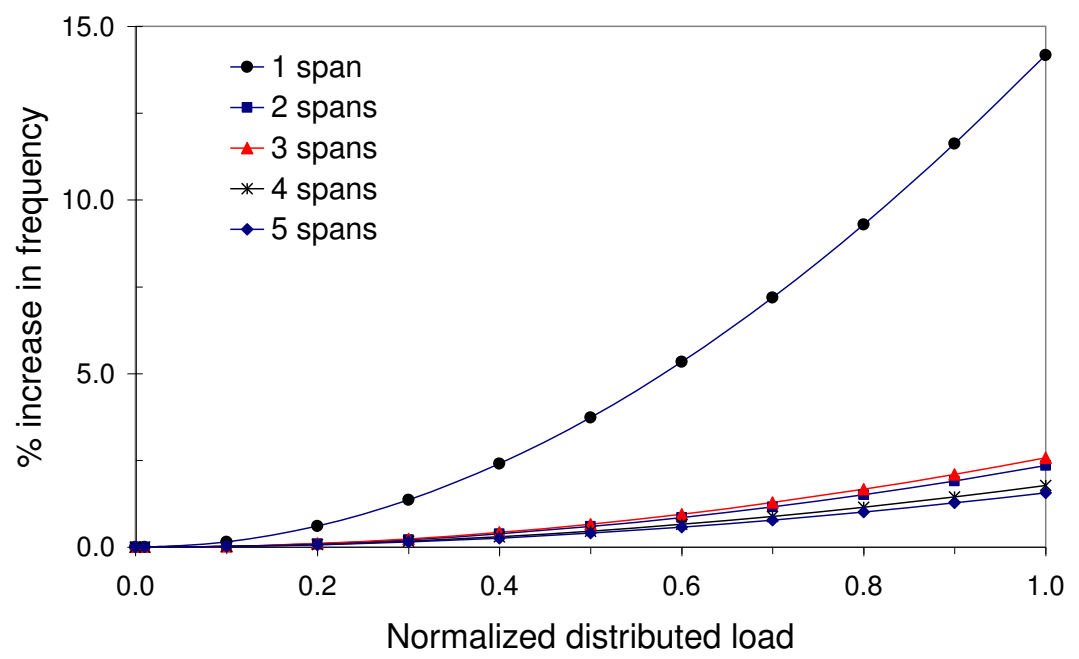

Figure 6: Relationship between distributed dead load and change in beam fundamental frequency for different number of spans.

In practice, multi-span beams may be subjected to dead loads which are not acting on all spans. So, the effect of dead load on natural frequencies of beams with different cases of loadings is investigated. Different cases of loadings of distributed loads are investigated for multi-equal-span beams. Figure 7 illustrates six cases of uniform dead loadings on five-equal-span beam from Case I to Case VI. Indeed, these six cases represent distributed loads on one, two, three or five spans which may be adjacent or alternative. 


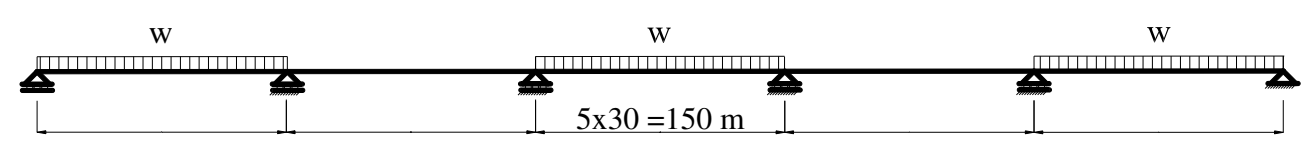

Case I

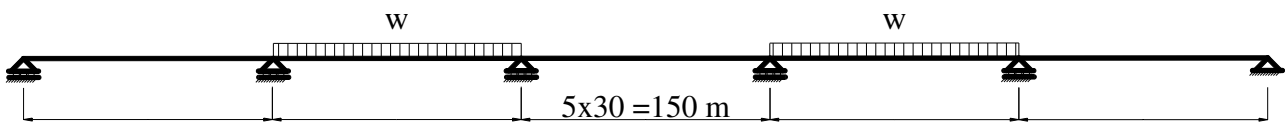

Case II

W

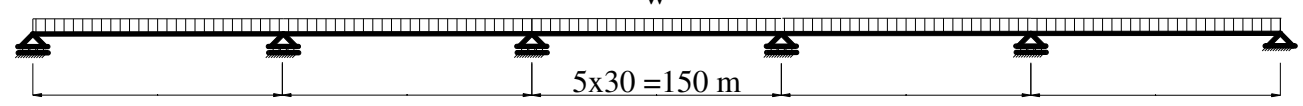

Case III

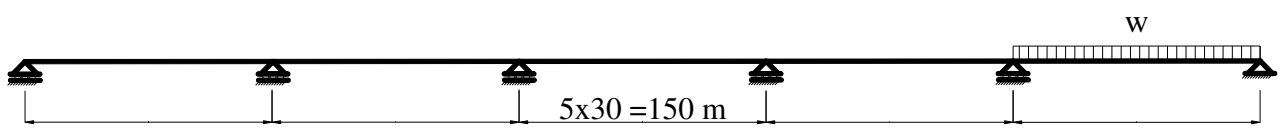

Case IV

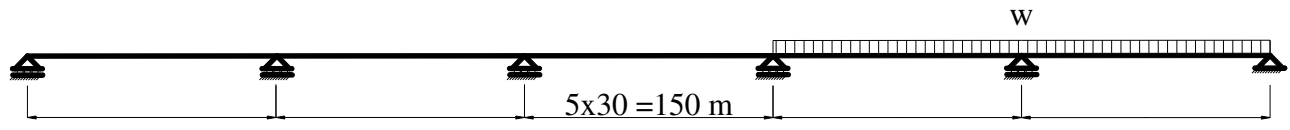

Case V

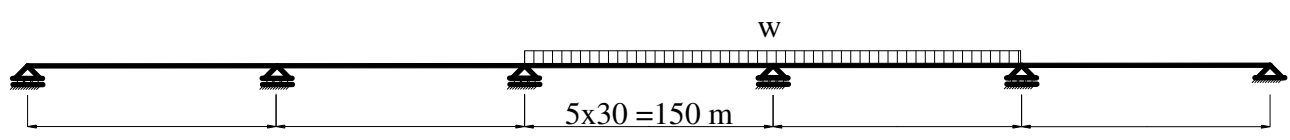

Case VI

Figure 7: Cases of loadings for five-equal-span beam.

The relationship between the normalized distributed dead load and the change in natural frequencies of five-equal-span beam with different cases of loadings is plotted in Figure 8. It is clear that the beam frequencies increase with the increase of dead loads for all cases of loadings. Also, it is shown that the effect of dead load on beam frequencies depends on cases of loadings. While Case I gives the maximum increase in beam fundamental frequency, Case VI gives the minimum increase in frequency. Also, Case III, which represents dead loads on all spans, does not give the maximum change in beam fundamental frequency. Indeed, from Fig. 8 it can be inferred that the case of loading which provides maximum positive bending moment between supports leads to maximum change in beam frequencies, such as Case I and Case II. However, loading adjacent spans diminish the effect of dead load on beam frequencies. Thus, the case of loading which provides maximum negative bending moment at supports leads to minimum change in frequencies, such as Case V and Case VI. 


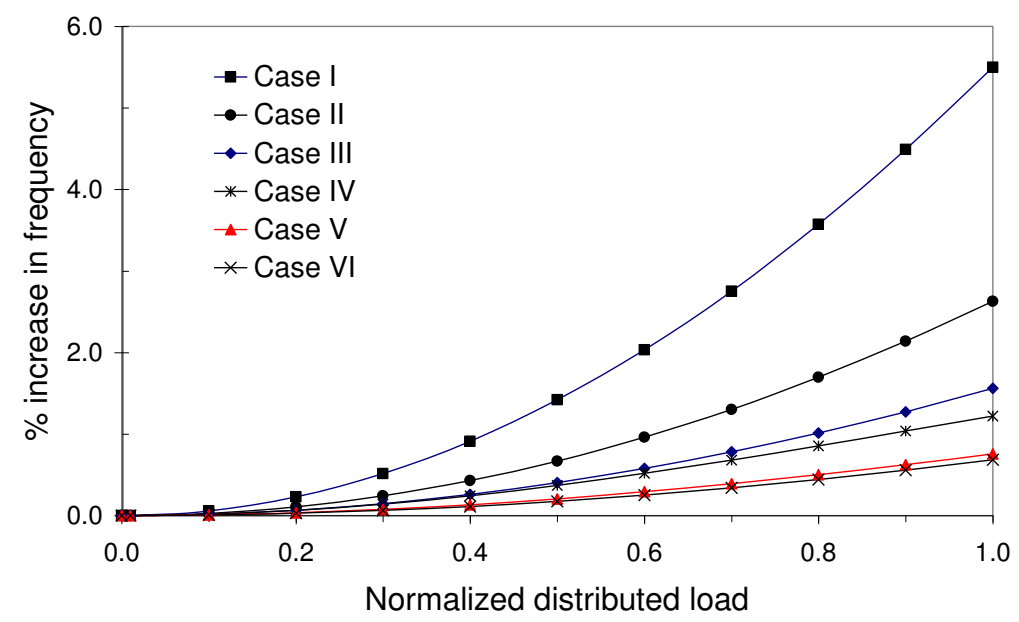

Figure 8: Relationship between distributed dead load and change in fundamental frequency of five-equal-span beam for different cases of loadings.

\section{CONCLUSIONS}

This study is concerned with parametric study of the effect of dead loads on the natural frequencies of beams. A careful numerical study is carried out by using the finite element technique. The study includes two types of dead loads; distributed and concentrated loads. The first ten mode frequencies are studied for each model. Based on the numerical results, the following conclusions can be drawn:

(1) Both distributed and concentrated loads have considerable influence on the lower frequencies of beams, especially the fundamental one and this effect increases with the increase of dead load. However, the effect of dead load may be neglected for frequencies higher than the first five natural frequencies.

(2) The longer the span the more effect of dead load on beam frequencies although the beam frequencies decrease with the increase of beam length.

(3) The higher the cross sectional moment of inertia the lesser the effect of dead load on change of beam frequencies. However, beams with higher cross sectional inertia have higher stiffness and consequently have higher frequencies.

(4) The percentage change in beam frequencies due to specific dead load does not depend on values of modulus of elasticity or mass density.

(5) The effect of dead load is maximum for single span beam and is smaller for multi-equal-span beams with all spans loaded with the same load value.

(6) In multi-equal-span beams, the case of loading which provides maximum positive bending moment between beam supports leads to maximum change in frequencies. However, loading adjacent spans diminish the effect of dead load on beam frequencies and consequently, the case of loading which provides maximum negative bending moment at supports leads to minimum change in frequencies. 
Indeed, although dead loads increase the induced stresses in beams, they enhance their dynamic behaviour due to their stiffening effect. So, dead loads should be taken into account for beams with less stiffness, especially in vibration-based damage detection methods using resonant frequencies.

\section{REFERENCES}

[1] Ewins, D. J.: "Modal Testing: TheOry And PracticE", Wiley, New York, 313 pp., (1984).

[2] Doebling, S. W., Farrar, C. R., Prime, M. P., and Shevitz, D. W.: "DAmage IDENTIFICATION AND HEALTH MONITORING OF STRUCTURAL AND MECHANICAL SySTEMS From CHANGES IN THEIR VibRATION CHARACTERISTICS", A Literature review, LA-13070-MS, (1996).

[3] Salawu, O. S.: "Detection of Structural Damage Through Changes in FREQUENCY”, A review, Engineering Structures, Vol. 19, No.9, pp. 718-723, (1997).

[4] Chandrasekaran, A. R.: "LIVE LOAD EFFECT OF DYNAMIC RESPONSE OF STRUCTURES”, J. Structural Division, ASCE, Vol. 95(4), pp. 649-660, (1969).

[5] Thomson, W. T.: "TheORY OF Vibration With APPliCATiONs", 3rd edition, Englewood Cliffs, New Jersey, 467 pp., (1988).

[6] Takabatake, H.: "EFFECT OF DEAD LOADS ON NATURAL FREQUENCIES OF BEAMS”, J. Structural Engineering, ASCE, Vol. 117(4), pp. 1039-1052, (1991).

[7] Zhou, S. J. and Zhu, X.: "ANALYSIS OF EFFECT OF DEAD LOADS ON NATURAL FREQUENCIES OF BEAMS USING FINITE-ELEMENT TECHNIQUE”, J. Structural Engineering, ASCE, Vol. 122(5), pp. 512-516, (1996).

[8] Takabatake, H.: "EFFECTS OF DEAD LOADS IN DYNIMIC PlATES", J. Structural Engineering, ASCE, Vol. 118 (1), pp. 35-51, (1992).

[9] Zhou, S. J.: "LOAD-INDUCED STIFFNESS MATRIX OF PlateS", Canadian J. Civil Eng., CJCA, Vol. 29, pp. 181-184, (2002).

[10] Cornil, M.-B., Capolungo, L., Qu, J., and Jairazbhoy, V. A.: "FreE VIBRATION of A BeAm SubJected to LARGe Static Deflection”, J. Sound and Vibration, Vol. 303(3-5), pp. 723-740, (2007).

[11] MARC Analysis Research Corporation, Volumes; A, B, and C, Version 2001, (2001).

[12] MARC Analysis Research Corporation, Mentat User's Guide, Version 2001, (2001).

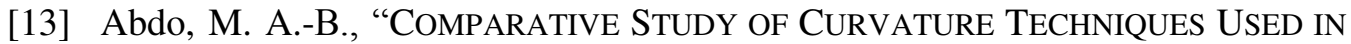
DAMAGE IDENTIFICATION", International Conference on Structural \& Geotechnical Engineering and Construction Technology, IC-SGECT '04, Mansoura, Egypt, pp. 73-86, (2004).

\section{دراسة بارا مترية لتأثير الأحمال الميتة على الترددات الطبيعية للكمرات}

ظهرت في الآونة الأخيرة العديد من الطرق لاكتشاف التلفيات باستخدام التغيرات في الخواص الديناميكية للمنشآت (التردد الطبيعي، شكل الاهتزاز ، معاملات إخماد الاهتزاز)؛ وذلك للوقوف على حالة المنشأ 
وأماكن التلفيات. لكن لوحظ عموماً أن معظم هذه الطرق لا تأخذ في الاعتبار تأثنير التغير في العوامل

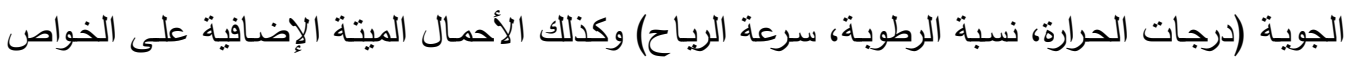

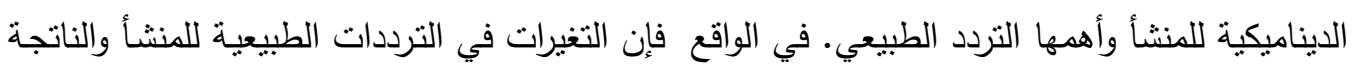

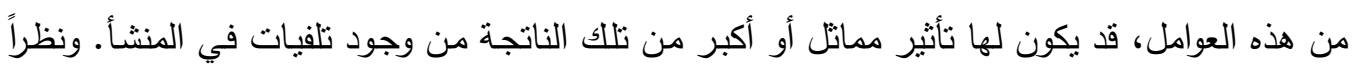

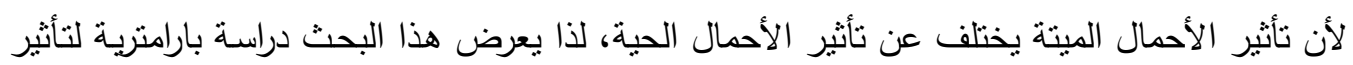

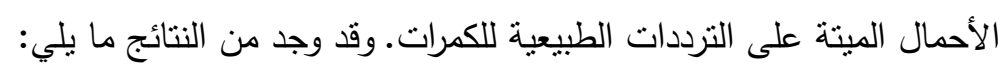
• الأحمال الميتة (الموزعة أو المركزة) نؤدي إلى زيادة معتبرة في الترددات الطبية ولئية الأساسية

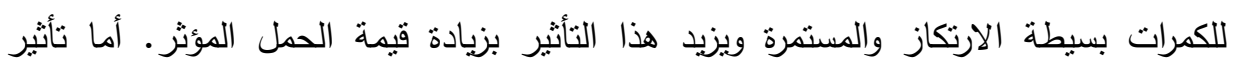
الأحمال الميتة فيقل بزيادة الرتبة ويمكن إهماله للترددات الأعلى من الرتبة الخامسة.

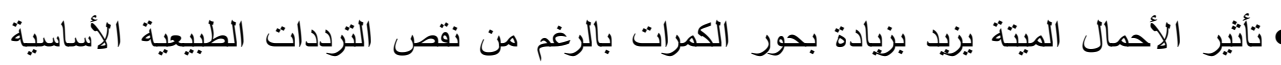

$$
\text { للكمرات بزيادة بحورها. }
$$

• زيادة عزم القصور الذاتي لمقطع الكمرة يقلل من نأثير الأحمال الميتة على الترددات الطبيعية لهذه الكمرات بالرغم من أن هذه الكمرات لها كزازة كبيرة وبالتالي تردداتها عالية.

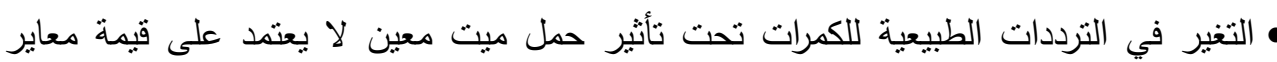
المرونة أو كثافة مادة الإنشاء. • تأثير الأحمال الميتة يكون أكبر ما يمكن للكمرة ذات البحر الواحد ويقل بزيادة عدد بحور الكمرات

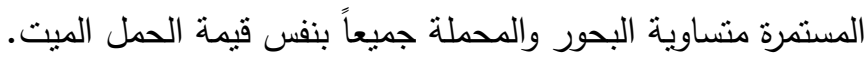

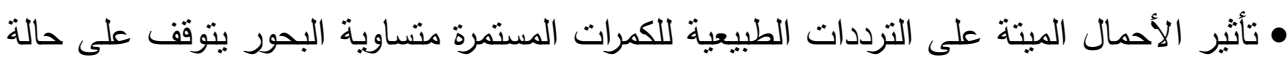

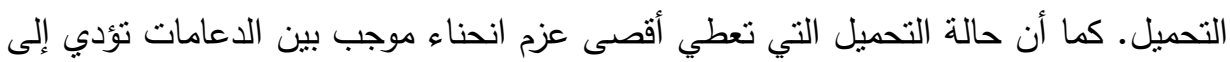

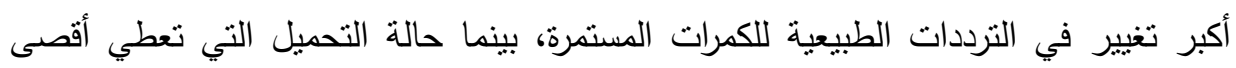
عزم انحناء سالب فوق الدعامات تؤدي إلى أقل تغيير في الترددات الطبيعية لهذه الكمرات.

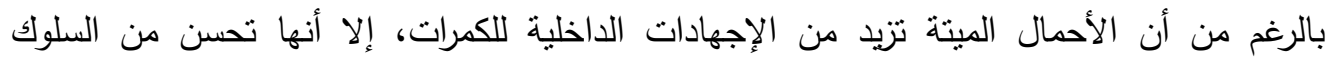

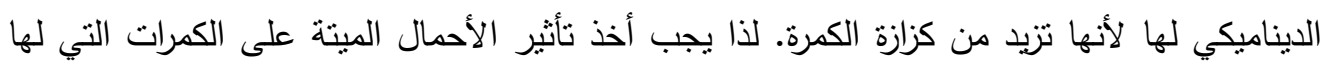
كزازة ضعيفة خصوصاً في طرق اكتثاف تلفيات المنشآت باستخدام التغيرات في تردداتها الطبيعية. 